\title{
PENDUGAAN NILAI HERITABILITAS UKURAN TUBUH PADA UMUR SAPIH DAN UMUR SETAHUN SAPI BALI DI BALAI PEMBIBITAN TERNAK UNGGUL SAPI BALI, JEMBRANA, BALI
}

\section{HERITABILITY ESTIMATION OF BODY SIZE AT WEANING AGE AND FIRST YEAR OF AGE ON BALI CATTLE IN BALAI PEMBIBITAN TERNAK UNGGUL SAPI BALI, JEMBRANA, BALI}

\author{
Ahmad Anwar Baiduri, Sumadi*, dan Nono Ngadiyono \\ Fakultas Peternakan, Universitas Gadjah Mada, Jl. Fauna No. 3, Bulaksumur, Yogyakarta, 55281
}

\section{INTISARI}

Tujuan dari penelitian adalah untuk mengetahui nilai heritabilitas ukuran tubuh meliputi panjang badan, tinggi gumba dan lingkar dada pada umur sapih dan umur setahun sapi Bali di Balai Pembibitan Ternak Unggul (BPTU) Sapi Bali, Jembarana, Bali. Data yang digunakan adalah 120 catatan ukuran tubuh sapi Bali pada umur sapih dan umur setahun dari tahun 2006 sampai 2010. Data ukuran tubuh umur sapih dan umur setahun dianalisis untuk mendiskripsikan nilai rata-rata dan standar deviasi. Nilai heritabilitas diduga dengan menggunakan metode korelasi saudara tiri sebapak dengan metode Rancangan Acak Lengkap pola searah. Hasil estimasi tersebut menunjukkan bahwa rata-rata ukuran tubuh panjang badan, tinggi gumba dan lingkar dada pada umur sapih berturut-turut yaitu 94,70 $\pm 4,42$; $98,31 \pm 4,34$ dan $120,78 \pm 7,39 \mathrm{~cm}$ serta pada umur setahun yaitu 95,90 $\pm 4,46 ; 100,28 \pm 4,35$ dan $125,45 \pm 7,40 \mathrm{~cm}$. Hasil pendugaan nilai heritabilitas dengan menggunakan metode korelasi saudara tiri sebapak untuk ukuran tubuh panjang badan, tinggi gumba dan lingkar dada pada umur sapih berturut-turut adalah 0,92 $\pm 0,0019 ; 0,76 \pm 0,0014$ dan $0,56 \pm 0,0013$ serta pada umur setahun yaitu $0,85 \pm 0,0015 ; 0,56 \pm 0,0010$ dan $0,44 \pm 0,0009$. Hasil dugaan nilai heritabilitas dapat disimpulkan bahwa nilai heritabilitas ukuran tubuh pada umur sapih dan umur setahun di Balai Pembibitan Ternak Unggul Sapi Bali, Jembrana, Bali bernilai tinggi.

(Kata kunci: Sapi Bali, Heritabilitas, Panjang badan, Tinggi gumba, Lingkar dada)

\section{ABSTRACT}

The aim of this study was to estimate the value of body size heritability including body length, wither height and heart girth on the weaning age and the yearly age of Bali cattle in Balai Pembibitan Ternak Unggul (BPTU) Sapi Bali, Jembarana, Bali. The data used were 120 records of Bali cattle body size at weaning age and yearly age from 2006 to 2010. The body size data at weaning age and yearly age were analyzed to find average value and deviation standard. Heritability value was calculated using Paternal Halfsib Correlation method with One-Way Classification Completely Randomized Design. Results showed that the average of body length, wither height and heart girth at weaning age were

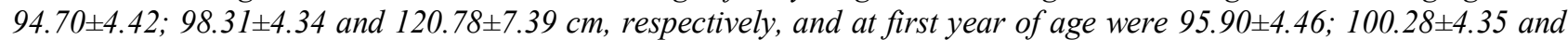
$125.45 \pm 7.40 \mathrm{~cm}$, respectively. The estimation of heritability for body length, wither height and heart girth at weaning

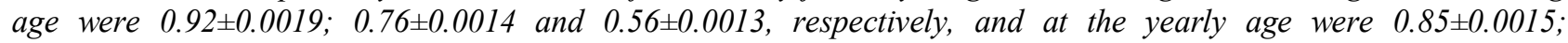
$0.56 \pm 0.0010$ and $0.44 \pm 0.0009$. It could be concluded that heritability value on the body size at weaning age and yearly age on Bali cattle in Balai Pembibitan Ternak Unggul Sapi Bali, Jembarana, Bali was categorized high.

(Key words: Bali cattle, Heritability, Body length, Wither height, Heart girth)

\section{Pendahuluan}

Bangsa (breed) sapi adalah sekumpulan ternak yang memiliki karakteristik tertentu yang sama. Atas dasar karakteristik tersebut, mereka dapat dibedakan dari ternak lainnya meskipun

\footnotetext{
* Korespondensi (corresponding author):

Telp. +6281328832260

E-mail: profsumadi@yahoo.co.id
}

masih dalam spesies yang sama. Karakteristik yang dimiliki dapat diturunkan ke generasi berikutnya. Menurut Hardjosubroto dan Astuti (1993) bangsa (breed) adalah tingkatan pengelompokan hewan dalam sistematika atau taksonomi dimana hewan tersebut telah memiliki ciri khas tertentu yang diwariskan seutuhnya kepada keturunannya. Menurut Pane (1990) genus sapi Bali termasuk Bibos yang merupakan spesies Bos sondaicus. Spesies Bos sondaicus khususnya sapi Bali memiliki ciri yang 
berbeda pada bentuk badannya yang lebih kecil. Penelitian Gunawan et al. (1998) menyatakan bahwa sapi Bali adalah domestikasi (penjinakan) dari banteng (Bibos banteng Syn. Bos sondaicus) yang telah terjadi sejak zaman prasejarah. Proses domestikasi tersebut diduga terjadi di pulau Jawa yaitu pada acara upeti raja-raja zaman dahulu. Namun, ada juga yang menduga bahwa Sapi Bali adalah asli berasal dari pulau Bali yang dalam perkembangannya dapat mempertahankan kemurniannya.

Sapi Bali memiliki warna bulu betina merah bata atau kuning tua, sapi jantan berbeda saat dewasa berwarna hitam sekali. Ciri-cirinya antara lain gumba tinggi dan memanjang, gelambir tumbuh mulai dari pertengahan leher, telinga tampak kuat dengan posisi berdiri, warna putih pada bagian bibir atas, pantat belakang, carpus dan tarsus ke bawah, telinga bagian dalam dan pada perut bagian bawah. Heat toleran baik, berat badan jantan $400 \mathrm{~kg}$ dan betina $350 \mathrm{~kg}$ (Blakely dan Bade, 1991).

Ukuran tubuh merupakan komponen pertumbuhan karena sebagai hasil peningkatan jumlah sel (Ledger, 1978 cit. Mu'in, 2008). Ukuran tubuh menurut Irwin dan Clayton (1977) bahwa ukuran yang baik terdiri dari steer golongan ke-2 dan heifer siap potong. Data ukuran tubuh sangat diperlukan dalam pelestarian program seleksi ternak, beberapa data ukur tentang bagian-bagian badan atau tubuh tersebut antara lain panjang badan, tinggi gumba, tinggi pinggul, lingkar dada dan indeks kepala.

Heritabilitas merupakan istilah yang digunakan untuk menunjukkan bagian dari keragaman total dari sifat kuantitatif pada ternak (yang diukur dengan beragam dan variansi) dari suatu sifat yang diakibatkan oleh pengaruh genetik (Warwick et al., 1990). Heritabilitas merupakan suatu proporsi dari ragam genetik terhadap ragam fenotip. Bergantung pada cara menghitung proporsinya maka secara statistik, angka pewarisan dapat dinyatakan dalam berbagai bentuk persamaan, dalam arti luas dapat dinyatakan dengan $\mathrm{H}=\sigma_{\mathrm{g}}^{2} / \sigma_{\mathrm{p}}^{2}$ yang berarti proporsi dari ragam genetik terhadap ragam fenotip dan dalam arti sempit dinyatakan dengan $\mathrm{h}^{2}=\sigma_{\mathrm{a}}{ }^{2}$ / $\sigma_{\mathrm{p}}{ }^{2}$ yaitu dapat didefinisikan sebagai proporsi dari ragam aditif terhadap ragam fenotip (Hardjosubroto, 1994). Heritabilitas bukan merupakan nilai konstan, berkisar antara 0 sampai 1 , dengan klasifikasi 0 sampai 0,1 rendah, 0,1 sampai 0,3 sedang, dan lebih dari 0,3 termasuk tinggi (Dalton, 1980). Menurut Edey (1983) heritabilitas merupakan suatu koefisien yang dapat berubah menurut jenis ternak, sifat, populasi, bangsa, waktu, dan daerah.

Hasil penelitian terdahulu melaporkan bahwa ukuran tubuh sapi Bali berdasarkan data pada saat BPTU Sapi Bali bernama P3 Bali yaitu heritabilitas untuk ukuran tubuh lingkar dada 0,50 dan panjang badan 0,34 serta untuk tinggi gumba 0,60 (Supriyantono dan Irianti, 2007). Estimasi ini termasuk klasifikasi tinggi. Perubahan P3 Bali menjadi BPTU Sapi Bali membuat manajemen dan populasi berubah, sehingga perlu adanya estimasi heritabilitas ulang dengan populasi yang berbeda.

\section{Materi dan Metode}

Penelitian dilaksanakan pada bulan Juli sampai September 2011 di BPTU Sapi Bali, Jembrana, Bali. Materi yang digunakan dalam penelitian adalah 120 catatan ukuran tubuh yaitu tinggi badan (gumba), lingkar dada, panjang badan pada saat umur sapih dan umur setahun di lima tahun terakhir yang terdapat di BPTU Sapi Bali, Jembrana, Bali.

Data yang didapat yaitu data sekunder, dengan cara mengambil catatan ukuran tubuh pada saat umur sapih dan umur setahun di BPTU Sapi Bali tahun 2006 sampai 2009 kemudian ditambah catatan silsilah berdasarkan catatan sisilah sapi Bali yang dipelihara di BPTU Sapi Bali, Jembrana, Bali.

Data yang sudah dikumpulkan dianalisis dengan menggunakan metode korelasi saudara tiri sebapak dan metode Rancangan Acak Lengkap pola searah, kemudian dihitung nilai heritabilitasnya dengan faktor koreksi yang digunakan disesuaikan pada umur sapih adalah sebagai berikut:

$$
\begin{aligned}
& \mathrm{UT}_{\text {sapih (205) }}=\frac{\mathrm{UT} \text { (sapih)-UT (lahir) }}{\text { umur }} \times 205+\text { UT (lahir) (FKUI) } \\
& \mathrm{UT}_{\text {setahun (365) }}=\frac{\mathrm{UT} \text { (setahun)-UT (sapih) }}{\text { tenggang waktu }} \times 160+\mathrm{UT} \text { (205) }
\end{aligned}
$$

Keterangan:

$\mathrm{UT}_{\text {sapih (205) }}=$ ukuran tubuh umur sapih (205 hari) yang sudah dikoreksi ke umur sapih 205 hari dan umur induk

$\mathrm{UT}_{\text {setahun (365) }}=$ ukuran tubuh umur setahun (365 hari) yang sudah dikoreksi ke umur 365 hari

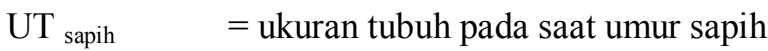

UT setahun = ukuran tubuh pada saat umur setahun

FKUI = faktor koreksi umur induk

\section{Analisis data}

Penghitungan nilai heritabilitas ukuran tubuh pada saat umur sapih dan umur setahun. Pendugaan angka pewarisan atau heritabilitas dilakukan dengan analisis variansi dengan menggunakan metode korelasi saudara tiri sebapak (paternal halfsib correlation). Pemisahan komponen ragam untuk menduga nilai heritabilitas dilakukan dengan analisis ragam menggunakan Rancangan Acak Lengkap pola searah (Completely Randomized 
Design One-Way Classification), dengan model

(Hardjosubroto, 1994): $\mathbf{Y}_{\mathbf{i k}}=\boldsymbol{\mu}+\boldsymbol{\alpha}_{\mathbf{i}}+\mathbf{e}_{\mathbf{i k}}$

Keterangan:

$\mathrm{Y}_{\mathrm{ik}}=$ pengamatan pada individu ke-k pada pejantan ke-i

$\mu \quad=$ rata-rata populasi

$\alpha_{\mathrm{i}} \quad=$ efek pejantan ke-i

$\mathrm{e}_{\mathrm{ik}}=$ penyimpangan efek lingkungan dan genetik yang tidak terkontrol dari setiap individu

Analisis sidik ragam dan pemisahan komponen variansi disajikan pada Tabel 1.

Tabel 1. Analisis ragam dan pemisahan komponen variansi (analysis of variance and separation of variance component)

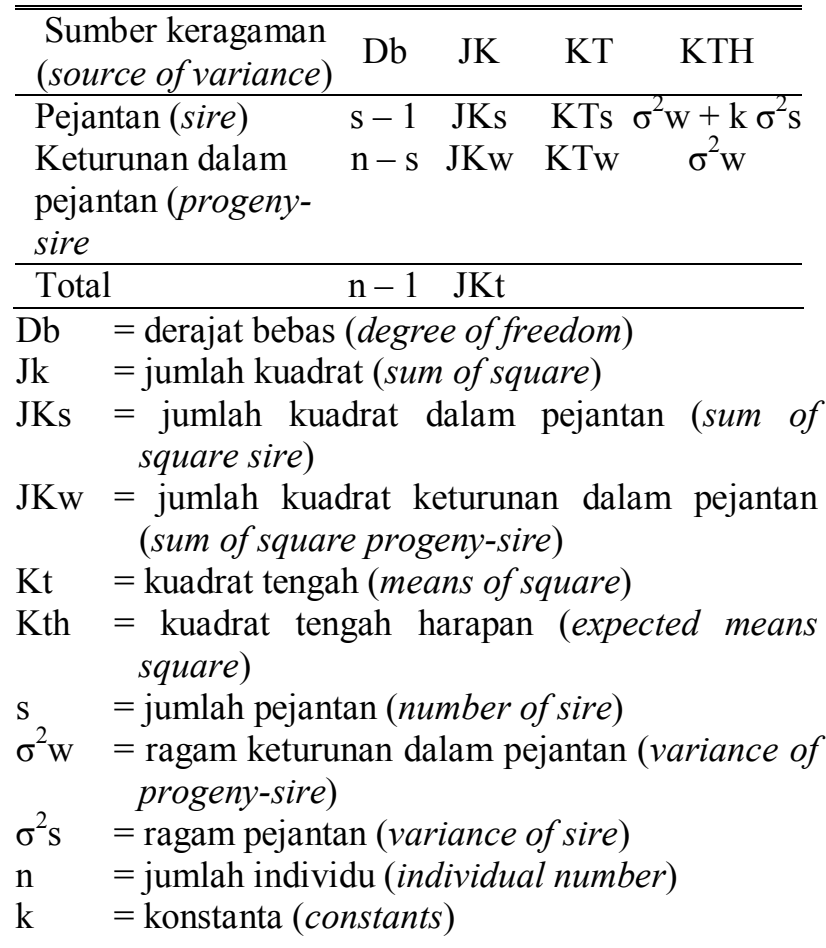

nilai $h^{2}=\frac{4 \sigma^{2} s}{\sigma^{2} s+\sigma^{2} w}$

$\sigma^{2} \mathrm{~W}=\mathrm{KTw}$ $\sigma^{2} \mathrm{~s}=\frac{\mathrm{KTs}-\mathrm{KTw}}{\mathrm{K}}$

$\mathrm{K}=\frac{1}{\mathrm{~S}-1}\left(\sum \mathrm{n}-\frac{\sum \mathrm{n}^{2}}{\sum \mathrm{n}}\right)$

Komponen-komponen ini, korelasi dalam kelas, yaitu suatu ukuran kemiripan antar saudara tiri, dapat ditentukan sebagai berikut:

$$
t=\frac{\sigma^{2} s}{\sigma^{2} s+\sigma^{2} W}
$$

Rumus menghitung heritabilitas adalah sebagai berikut (Warwick et al., 1990):

$$
\begin{aligned}
& h^{2}=4 \mathrm{t} \\
& \operatorname{SE}\left(h^{2}\right)=4 \sqrt{\frac{2(1-t)^{2}\{1+(k-1) t\}^{2}}{k(k-1)(s-1)}}
\end{aligned}
$$

$\mathrm{SE}=$ standard error

\section{Hasil dan Pembahasan}

Hasil estimasi nilai heritabilitas ukuran tubuh pada umur sapih dan setahun dengan metode saudara tiri sebapak pada sapi Bali tersaji pada Tabel 2.

Tabel 2 menunjukkan bahwa hasil nilai heritabilitas ukuran tubuh umur sapih dan setahun pada sapi Bali yang bernilai tinggi yaitu lebih dari 0,3 (Dalton, 1980). Hal ini berarti sifat-sifat ukuran tubuh tersebut dapat digunakan untuk kriteria seleksi, yaitu apabila calon pejantan dan induk diperoleh berdasarkan ukuran-ukuran tubuh di atas rata-rata populasi maka dapat diharapkan anak keturunannya akan mempunyai ukuran lebih di atas rata-rata pula. Di samping itu standard error relatif kecil dan lebih kecil dari nilai heritabilitas, artinya nilai heritabilitas tersebut handal atau dapat dipercaya sehingga layak untuk diaplikasikan di dalam kegiatan peningkatan mutu genetik sapi Bali

Tabel 2. Estimasi nilai heritabilitas ukuran tubuh sapi bali umur sapih dan umur setahun di BPTU Sapi Bali, Jembrana, Bali (heritability estimation of body size of Bali cattle at weaning age and one year old at BPTU Sapi Bali, Jembrana, Bali)

\begin{tabular}{lcc}
\hline \hline \multirow{2}{*}{ Ukuran tubuh (body size) } & \multicolumn{2}{c}{$\mathrm{h}^{2} \pm \mathrm{SE}$} \\
\cline { 2 - 3 } & Umur sapih (weaning age) & Umur setahun (one year old) \\
\hline Lingkar dada (heart girth) & $0,56 \pm 0,0013$ & $0,44 \pm 0,0009$ \\
Panjang badan (body length) & $0,92 \pm 0,0019$ & $0,85 \pm 0,0015$ \\
Tinggi gumba (wither height) & $0,76 \pm 0,0014$ & $0,56 \pm 0,0010$ \\
\hline
\end{tabular}
$\mathrm{h}^{2}=$ heritabilitas, $\mathrm{SE}=$ standard error. 
melalui seleksi ukuran tubuh, sebab ukuran tubuh mempunyai korelasi genetik yang tinggi dan positif dengan berat badan, maka peningkatan ukuran tubuh juga akan meningkatkan berat badan sapi tersebut (Warwick et al., 1990). Hasil ini akan sangat baik untuk seleksi sapi Bali di peternakan rakyat dengan berdasarkan ukuran tubuh tetapi tujuannya untuk meningkatkan berat badan, sebab pada peternakan rakyat umumnya tidak tersedia timbangan, tetapi ukuran tubuh dengan mudah dapat diperoleh dengan melatih peternak sapi Bali.

Hasil penelitian ini berbeda dengan hasil penelitian Supriyantono dan Irianti (2007), di tempat yang sama, yaitu heritabilitas lingkar dada 0,50 , panjang badan 0,34 dan tinggi gumba 0,60 , juga berbeda dengan hasil penelitian Baco et al. (1998) cit. Soeroso (2004) pada sapi Jepang yaitu heritabilitas lingkar dada $0,33 \pm 0,04$. Hal ini diduga disebabkan adanya perbedaan populasi, tahun penelitian, dan juga metode estimasi yang berbeda (Warwick et al., 1990). Di samping itu, hasil estimasi nilai heritabilitas ukuran-ukuran tubuh pada sapi Bali di BPTU Jembrana, Bali ini sesuai dengan hipotesis dan layak untuk digunakan sebagai dasar seleksi untuk meningkatkan mutu genetik, yaitu seleksi berdasarkan ukuran tubuh tetapi tujuannya meningkatkan berat badan.

\section{Kesimpulan dan Saran}

\section{Kesimpulan}

Hasil estimasi nilai heritabilitas ukuran tubuh sapi Bali pada umur sapih dan setahun di BPTU Sapi Bali, Jembrana, Bali adalah tinggi dan ukuran tubuh yaitu lingkar dada, panjang badan dan tinggi gumba dapat digunakan sebagai kriteria seleksi untuk meningkatkan mutu genetik.

\section{Saran}

Estimasi parameter genetik pada sifat-sifat yang mempunyai nilai ekonomi tinggi pada sapi potong sebaiknya dihitung setiap 5 tahun sekali dengan jumlah data minimal 500 dengan macammacam metode.

\section{Daftar Pustaka}

Blakely, J. dan D.H. Bade. 1991. Ilmu Peternakan. Edisi IV. Gadjah Mada University Press. Yogyakarta.

Dalton, L.E. 1980. An introduction to Practical Animal Breeding. Granada Publ., Ltd. Technical Book Devilion, London.

Edey, T.N. 1983. Tropical Sheep and Goat Production. Australian Universities International Development Program (AUIDP), Canberra.

Gunawan, D. Pamungkas, dan L. Affandhy. 1998. Sapi Bali, Potensi, Produktivitas dan Nilai Ekonomi. Kanisius. Yogyakarta.

Hardjosubroto, W. 1994. Aplikasi Pemuliabiakan Ternak di Lapangan. PT. Grassindo, Jakarta.

Hardjosubroto, W. dan J.M. Astuti. 1993. Buku Pintar Peternakan. PT. Grassindo, Jakarta.

Irwin, A.D and C.O. Clayton. 1977. The Feedlot. $2^{\text {nd }}$ ed. Lea and Febiger. Philadelphia.

Mu'in, M.A. 2008. Polimorfisme genetik growth hormone dan insulin-like growth factor-i serta efeknya pada pertumbuhan prasapih sapi potong di Indonesia. Disertasi. Program Pasca Sarjana Universitas Gadjah Mada. Yogyakarta.

Pane, I. 1990. Upaya peningkatan mutu genetik sapi Bali di P3 Bali. Prosiding Seminar Nasional Sapi Bali. Bali: 20-22 September 1990.

Soeroso. 2004. Performans sapi Jawa berdasarkan sifat kuantitatif dan kualitatif. Tesis. Fakultas Peternakan, Universitas Diponegoro Semarang.

Supriyantono, A. dan B.W. Irianti. 2007. Peningkatan mutu genetik sapi Bali melalui pengembangan program pemuliaan. Available at http/www.ejournal.umm.ac. id/index.php/.../149_umm_scientific ejournal.doc. Accession date: 23 September, 2011.

Warwick, E.J., J.M. Astuti, dan W. Hardjosubroto. 1990. Pemuliaan Ternak. Gadjah Mada University Press, Yogyakarta. 